This paper (accepted manuscript) has been accepted for publication and will appear in a revised form subsequent to editorial input by Cambridge University Press. Link: https://www.cambridge.org/core/journals/british-journal-of-music-education

Cite to this: Angel-Alvarado, Rolando; Belletich, Olga; Wilhelmi, Miguel R. (2020). Exploring motivation in music teachers: The case of three primary schools in Spain. British Journal of Music Education, 37(3), 196-206. doi:10.1017/S0265051720000145

\title{
Exploring motivation in music teachers: The case of three primary schools in Spain
}

Music teachers enjoy carrying out teaching tasks; indeed, such pleasure may be perceived even when authoritarian pedagogical methods are applied. In this study, we will explore music teacher motivation in classroom settings, collecting data from three educators through psychological scales, lesson observations, and personal interviews. Results indicate that teacher motivation in classroom settings is affected by five internal and five external factors. Therefore, the study allows concluding that teacher motivation is also satisfied or thwarted by ideas that school members have about music education. Some practical implications are suggested.

Keywords: music teacher motivation, self-determination theory, autonomous motivation, basic psychological needs, teacher beliefs.

\section{Introduction}

This study aims to explore the motivation of music teachers in classroom settings because, according to Gabnyté and Strakšiené (2014), music teachers enjoy conducting lessons even when authoritarian teaching methods are applied. To better understand this, the behaviour of three music teachers is analysed in qualitative terms from a perspective focused on selfdetermination theory (Evans, 2015; Deci \& Ryan, 2016; Ryan \& Deci, 2017; AngelAlvarado \& Álamos, 2018). This theory establishes that autonomous motivation involves a sense of will when making decisions, while controlled motivation is related to feelings of pressure during a task. Specifically, autonomous motivation is inherently linked to intrinsic 
motivation and identified regulation (Gagné \& Deci, 2005), which means that pleasure is perceived even when activities entail no personal benefit. Thus, higher autonomous motivation would imply an internalisation of self-determined behaviours because actions could be based on the perceived pleasure (Ryan \& Deci, 2017).

Self-determination also depends on the satisfaction of three basic psychological needs (Ryan \& Deci, 2017). Firstly, autonomy implies the desire for choice as well as the feeling of willpower during an activity. Secondly, competence entails the desire for optimal interaction in order to achieve desired results within a workplace. Finally, relatedness involves an attunement to the social environment through interpersonal knowledge. It is important to consider that the satisfaction of the need for autonomy is decisive in establishing whether the behaviour is self-determined or not (Gagné \& Deci, 2005), as it indicates the degree of identification, assimilation, or integration of this behaviour.

\section{Method}

Holistic Architecture for Music Education (HAME; Angel-Alvarado, Wilhelmi, \& Belletich, 2019), an interdisciplinary research approach that carries out empirical studies in the field of music education, was the framework selected for the present study. This holistic research approach involves mixed research methods, reporting qualitative findings through an objective portrait because HAME possesses internal consistency by reasons linked to its four-phase structural research design (Angel-Alvarado et al., 2019). This means that the sample size becomes irrelevant because, strictly speaking, HAME's internal validity is demonstrated through a contrast process between empirical findings and theoretical framework (Angel-Alvarado, Wilhelmi, \& Belletich, 2018).

\section{Sample}

The investigation took place in Spain within the Chartered Community of Navarre; three music teachers (Table 1) participated of their own accord. Participation agreements were regulated in conformity with criteria established in a formal invitation (sent to each primary school). The teachers' group is understood as a nonprobability sample, so the construction of generalisations was not feasible. The sampling unit was selected according to three strategic criteria linked to convenience samples (Kline, 2005). Firstly, participants were working in some Navarrese primary schools situated in urban areas. Secondly, all teachers 
participated of their own accord because it is not appropriate to evaluate autonomous motivation with criteria linked to behavioural control. Lastly, data collection was conducted in November 2017.

All participant schools have music classrooms. Likewise, all schools have appropriate musical resources for conducting music lessons. There was a piano, sheet music stands, Orff instrument set, posters related to music theory, projector, and sound system. Moreover, students had recorders and exercise books. Finally, music education was a compulsory subject at all participant schools, including 45 minutes per week at the observed primary education level, i.e., the sixth level (age 11-12). According to the International Standard Classification of Education (UNESCO, 2012), the observed education level corresponds to the last year of Level 1.

Table 1. Personal information from participant Navarrese teachers.

\begin{tabular}{llll}
\hline & Teacher 1 & Teacher 2 & Teacher 3 \\
\hline Age & 50 years old & 39 years old & 38 years old \\
Bachelor's degree & In Music & In Music & In Music Education \\
Master's degree & In Education & In Music Education & No Master's degree \\
Teaching experience & 25 years & 16 years & 13 years \\
Experience in the current school & 21 years & 11 years & 10 years \\
\hline
\end{tabular}

Source: Own elaboration.

\section{Measures and tools}

Teacher motivation. The Spanish version of the Work Tasks Motivation Scale for Teachers (WTMST; Fernet, Senécal, Guay, Marsh, \& Dowson, 2008; Ruíz, 2015) was applied within the framework of autonomous motivation. The measure consists of six items that are distributed across two subscales: intrinsic motivation (three items; e.g., 'I like doing this task') and identified regulation (three items; e.g., 'it is important for me to carry out this task'). These six items are rated on a 7-point Likert-type scale ranging from 1 (does not correspond at all) to 7 (absolutely corresponds). In the present study, the Spanish version of the WTMST had a Cronbach alpha coefficient of .767, which is acceptable because it is greater than 70 (Davenport, Davison, Liou, \& Love, 2015).

Teacher's basic psychological needs. The Basic Psychological Needs Scale for Teachers (BPNS-T; Angel-Alvarado, Wilhelmi, \& Belletich, 2020) was applied in this study. The measure consists of seven items distributed across three subscales: need for autonomy (two 
items; e.g., 'I can make decisions about my syllabus'), need for competence (three items; e.g., 'students say that I am a good teacher'), and need for relatedness (two items, e.g., 'I like people I work with'). These seven items are rated on a 5-point Likert-type scale ranging from 1 (does not correspond at all) to 5 (absolutely corresponds). In this study, the BPNS-T had a Cronbach alpha coefficient lower than .70, which was accepted because, considering the sample size, the homogeneity of variance was expected.

Understanding classroom setting. Structured observations focused on different internal factors of music lessons, such as facilities and educational resources, as well as the number of times the lesson was interrupted. Likewise, in an attempt to note teaching models, our observations included the three key assessment questions based on understanding in music education (Fautley, 2010): identify (e.g., Does the teacher inform the students of the lesson's educational objective?), quantify (e.g., Does the teacher explain to the students the quantification of the summative assessment criteria?), and help (e.g., Is the teacher's feedback linked to the lesson's educational objective?).

Semi-structured interview with the teacher. Each observed teacher participated in an interview that established two aspects of their pedagogical practise. Firstly, the interview delved into the authenticity of the pedagogical reflection, serving as a moment when teachers self-assessed their performance during the observed lesson (e.g., 'Which were the positive and negative elements that influenced in your teaching task during the observed lesson?'). The second section encompassed the teachers' perception about the educational reality, both in local and general terms (e.g., 'Do you think that music education is appreciated in your school community?'). It also inquired about the pedagogical profile of teachers (e.g., 'Which is your pedagogical model in music education?').

\section{Data collection procedures}

Before beginning the observed lesson, each educator was asked to complete the Spanish version of the WTMST and the BPNS-T, this was done in a quiet environment. Five minutes was the maximum completion time. Subsequently, teachers carried out their lessons as usual. Meanwhile, the researcher observed the teaching session from the back of the classroom. After the lesson, the teachers participated in personal interviews in which they could self-assess their pedagogical performances in the observed sessions and discuss 
other factors that, in their regard, have an impact on their teaching activities. The duration of the interviews fluctuated between 18 and 32 minutes, which corresponded to Teacher 2 and Teacher 1, respectively. The interviews were recorded with permission of the same teachers, who authorised all data collected to be used and published for scientific purposes.

\section{Data analysis procedures}

The autonomous motivation was individually analysed for each participant through the Spanish version of the WTMST. According to the obtained mean, subscales of intrinsic motivation and identified regulation were transformed into ordinal variables with the intention of carrying out qualitative interpretations (Mellinger \& Hanson, 2017).

Considering that the maximum score in each subscale is 21 points, the said transformation implies the following three levels:

- High - the obtained mean is equal to or more than 19 points;

- Middle - the obtained mean is equal to or more than 16 points but lower than 19 points; and

- Low - the obtained mean is equal to or below 15 points.

Through the BPNS-T, basic psychological needs are also individually analysed in each teacher. According to the obtained mean, subscales of needs for autonomy, competence, and relatedness are transformed into ordinal variables in order to accomplish qualitative interpretations. Regarding subscales of needs for autonomy and relatedness, the maximum score is 10 points, implying the following three levels:

- High - the obtained mean is equal to or more than 8 points;

- Middle - the obtained mean is equal to or more than 5 points but lower than 8 points; and

- Low - the obtained mean is equal to or below 4 points.

Regarding the subscale of the need for competence, the maximum score is 15 points, which implies the transformation of the next three levels:

- High - the obtained mean is equal to or more than 13 points;

- Middle -the obtained mean is equal to or more than 10 points but lower than 13 points; and 
- Low - the obtained mean is equal to or below 9 points.

These ordinal variables are triangulated with data collected through observation of the lesson and a semi-structured interview with the intention of establishing autonomous motivation and the satisfaction/frustration of basic psychological needs in each teacher. These individual outcomes are compared in order to achieve the theoretical saturation of conceptual categories linked to autonomous motivation and basic psychological needs (Carrero, Soriano, \& Trinidad, 2012). The theoretical saturation leads to the writing of an emergent theory which would arise from the inductive perspective (San Martín, 2014).

\section{Results and discussion}

\section{Motivational categories}

Teacher 1 and Teacher 3 showed high levels of intrinsic motivation and identified regulation (Table 2). Specifically, Teacher 1 reported the highest level of intrinsic motivation, which means that this educator would perceive more personal pleasure in carrying out teaching tasks than others. Teacher 3 registered the highest level of identified regulation, so this educator would have more awareness than other teachers regarding the impact that teaching actions have on student development, both in personal and academic terms. Finally, Teacher 2 displayed middle levels of intrinsic motivation and identified regulation, although those averages are in the border between middle and high levels. Therefore, these outcomes indicate that music teachers enjoy conducting teaching tasks and are committed to the learning of their students.

Table 2. Descriptive statistics of motivational categories, according to the output by participant teachers.

\begin{tabular}{lllll}
\hline & & Teacher 1 & Teacher 2 & Teacher 3 \\
\hline \multirow{2}{*}{ Intrinsic } & Level & High & Middle & High \\
motivation & Range & 0 & 2 & 1 \\
& Mean & 21 & 18 & 20 \\
\hline \multirow{2}{*}{ Identified } & Level & High & Middle & High \\
regulation & Range & 2 & 2 & 1 \\
& Mean & 19 & 18 & 20 \\
\hline
\end{tabular}

Data collected through the WTMST' Spanish version.

Source: Own elaboration.

These results are intertwined with data collected during the observation of the lessons and interviews, with the following outcomes. In the case of Teacher 1, working hours for music 
education have been reduced over time. When Teacher 1 began to teach, two lessons per week were administratively scheduled, each one had a duration time of 50 minutes. Nowadays, students only receive one lesson per week, with a duration of 45 minutes. In this new scenario, Teacher 1 started to teach a school subject linked to education in moral values in order to complete his timetable. This professional situation might explain the highest level of intrinsic motivation of Teacher 1, as music teaching would not be just an agreeable activity, but also may be understood as an escape mechanism from other pedagogical responsibilities.

Regarding identified regulation, Teacher 1 expressed that, on the one hand, 'the reduction of the duration of the lessons also has implications for students as they have less time for learning music' (2017) and, on the other hand, 'students' musical preferences would be considered in teaching tasks' (2017). For this reason, Teacher 1 introduced the worldfamous song entitled Despacito into the observed lesson. These personal beliefs reinforce identified regulation because Teacher 1 is aware that teaching actions have an impact on students' attitudes.

Teacher 2 prioritises 'the music notation and classical composers' (2017). Also, the recorder is considered as 'essential in the music reading because it implies playing musical notes' (Teacher 2, 2017). In this pedagogical context, the educator would not perceive harmony with the school community because, on the one hand, the school administration has not provided enough funding for music education and, on the other hand, 'colleagues and students understand music education as a trivial subject that is positioned in the curriculum in order to break down the school routine' (Teacher 2, 2017). The intrinsic motivation of Teacher 2 is then declining because this participant would feel uneasy within the school community.

Concerning identified regulation, Teacher 2 expressed that 'students' musical tastes are considered in teaching tasks as much as possible, as learners can suggest repertoires' (2017). However, Teacher 2 emphasised that 'differentiated assessment is not applied' (2017). This means that assessing activities are not necessarily tailored to the skills or interests of the students. In cases when learners have problems acquiring or developing a musical competence, Teacher 2 stated that 'differentiated instruction is implemented' 
(2017), but, at the time of the assessment, all learners are assessed under the same criteria and parameters. As a result, Teacher 2 is still not aware that those pedagogical actions have an impact on students' minds.

In the case of Teacher 3, intrinsic motivation reached a high level because Teacher 3 'feels loved by the school community' (2017). Teacher 3 also perceives that 'the school administration supports music education because it provides facilities and educational resources whenever possible' (2017) and, as a result, the participant feels comfortable in the workplace.

Regarding identified regulation, Teacher 3 highlighted 'the importance of tailoring teaching tasks to the students' sociocultural level and their interests, even when the educator does not enjoy songs' (2017). Teacher 3 also emphasised that, although musical knowledge is important in the subject, ethical and social competencies are also relevant because the mission of music education 'should be oriented toward the holistic training' (Teacher 3, 2017). In this context, the pedagogy would be oriented to music-making (Elliott \& Silverman, 2015) because learners are living their musical experiences. These results would explain why Teacher 3 is more committed to student learning than the other observed participants.

In these three cases, external factors are affecting motivational categories linked to autonomous motivation. The intrinsic motivation of Teacher 2 and Teacher 3 is influenced by the school community, while the intrinsic motivation of Teacher 1 is affected by the Spanish education policy. Regarding identified regulation, the three cases make reference to the affective bond between teachers and students because identified regulation implies, above all else, personal identification with the worth or meaning of the teaching/learning activity (Gagné \& Deci, 2005). The ongoing results demonstrate that the music teachers' autonomous motivation is high, but it is affected by multiple factors of social complexity.

\section{Basic psychological needs}

The three participants have shown high levels of satisfaction in their needs for autonomy and relatedness (Table 3). All music teachers perceived autonomy in defining the syllabus and teaching tasks in the classroom. Likewise, they noticed emotional harmony and confidence with their peers. Regarding the need for competence, Teacher 1 and Teacher 3 
displayed high satisfaction levels, such that both participants feel professional confidence in carrying out teaching tasks in the classroom. However, Teacher 2 reported a low satisfaction level concerning the need for competence because this teacher provided no answer to item number 4 ('Students say that I am a good teacher') and number 7 ('My students value and appreciate me) from BPNS-T. During the interview, Teacher 2 recognised that, on the one hand, 'teaching tasks are not necessarily tailored to learners' skills' (2017) and, on the other hand, 'learners would not take the music education seriously because they understand it as a school time for fun' (Teacher 2, 2017). These statements would be related to the non-answered items, which would correspond to low points on the Likert-type scale.

These results are completed by the data collected during the observation of the lessons and interviews. In the need for autonomy, all music teachers are satisfied because they have, to a certain extent, autonomy in carrying out their teaching tasks. Nonetheless, there are differences among the participants. On the one hand, Teacher 1 and Teacher 2 autonomously decided to conduct many activities during the observed lessons, and they are the ones who choose the repertoire. Also, they implemented one-on-one assessments.

Table 3. Descriptive statistics of the satisfaction levels of basic psychological needs, according to the output by participant teachers.

\begin{tabular}{lllll} 
& & Teacher 1 & Teacher 2 & Teacher 3 \\
\hline \multirow{3}{*}{ Satisfaction in autonomy } & Level & High & High & High \\
& Range & 0 & 0 & 0 \\
& Mean & 10 & 10 & 10 \\
\hline \multirow{3}{*}{ Satisfaction in competence } & Level & High & Low & High \\
& Range & 1 & 4 & 1 \\
& Mean & 14 & 4 & 14 \\
\hline \multirow{3}{*}{ Satisfaction in relatedness } & Level & High & High & High \\
& Range & 1 & 0 & 0 \\
& Mean & 9 & 10 & 10 \\
\hline
\end{tabular}

Data collected through the BPNS-T.

Source: Own elaboration.

On the other hand, Teacher 3 prepared a progressive syllabus that ends up with the emulation of a famous TV show, where 'students have selected their own songs' (Teacher 3, 2017) and provided constructive feedback to their classmates. Therefore, these results show that 'autonomy does not mean only freedom but also capacity to act' (Juntunen, 2017, p.10). Likewise, outcomes display that teacher satisfaction of the need for autonomy does not 
mean that teaching tasks will promote self-determined behaviours in students. Strictly speaking, Teacher 1 and Teacher 2 have satisfied the need for autonomy, but they have implemented activities based on controlled motivation since students cannot provide constructive criticism to their classmates or choose musical repertoires.

Regarding the need for competence, the three music teachers agreed that the weekly time for music education is a notorious problem as it is insufficient for thoroughly complying with the official curriculum. For instance, Teacher 2 expressed the view that 'we can carry out so many activities in music education, but with 45 minutes it is impossible' (2017). It is important to highlight that only Teacher 1 admitted a 'stress triggered by lack of time' (2017), implying that the time situation would have a direct impact on the quality of the teaching tasks conducted in the classroom (West, 2013).

In addition, the three music teachers indicated that student disruptions affected their lessons, but they mentioned different reasons. For instance, Teacher 2 blamed the 'weather' (2017), while Teacher 3 considered that 'students felt nervous in the observed lesson' (2017) and, lastly, Teacher 1 thought 'Spanish idiosyncrasy is responsible for student disruptions' (2017), complaining of exhaustion due to students' behaviour. In general, these responses reveal, in addition to lack of self-criticism and empathy, that participant teachers would not know their students, to the point that Teacher 1 and Teacher 2 are not capable of giving their learners constructive guidance because educators do not assume pedagogical responsibilities. In view of these outcomes, it is plausible to indicate that only Teacher 3 would provide an adequate guide to students, while the other participants only applied strategies linked to controlled motivation because they have not yet internalised identified regulation (Deci \& Ryan, 2016).

These differences between teachers are determinant in the area of pedagogical profiles. In the teaching task conducted by Teacher 3, students could choose their repertoires as well as give constructive advice to their classmates, such that the assessment is understood as a holistic process because students also have active participation. On the contrary, students of the other participant teachers have no chances for acquiring and developing those social competencies because assessments are carried out one-on-one and repertoires were selected only by teachers, taking into account student preferences. As a result, the need for 
competence is less satisfied than other basic psychological needs because some teachers are more focused on musicological contents than on holistic student training (Angel-Alvarado et al., 2019).

Regarding the need for relatedness, participant music teachers have expressed that the Spanish education policy does not support them with the minimal time resources for carrying out their teaching tasks. As a result, they perceive that the education system does not value their job activity because 'music teachers are so forgotten' (Teacher 3, 2017). Within the school community, Teacher 1 and Teacher 3 have frequently felt supported by principals, teaching staff, parents, and guardians. Their communities have provided as many resources as possible, respect music teaching, and appreciate student learning. For instance, Teacher 1 perceives 'the school administration's support in terms of work conditions' (2017). Meanwhile Teacher 2, who was considered as the exception, 'is hopeful for establishing a good relationship with the new school administration, despite the previous negative experiences' (2017). Teacher 2 also stated that the school educational project is determinant in terms of work conditions because the delivery of music tools and resources depends on the academic importance of music education in the school.

Given that all participant teachers have worked at the same school for more than 10 years, results would suggest that they have satisfied the need for relatedness. However, it would be inhibited due to the limited time established through the official curriculum and negative opinions provided by some members of school communities who undervalue music education, assigning it an irrelevant role. For instance, Teacher 2 stated that 'there is a mixture between music education and the teacher as a person. That is, my peers support me in personal terms. However, I see that music education is not a subject like the rest of the subjects at the school' (2017). These factors may suggest job isolation because teachers would have difficulties interacting with colleagues in working terms.

\section{Writing an emergent theory: The objective portrait}

In these three cases, intrinsic motivation and identified regulation are affected by multiple factors of social complexity. The autonomous motivation in teaching tasks does not depend only on the classroom setting, given that the interest that the school community expresses in supporting music education is also important. 
Only Teacher 3 shows self-determined behaviours because the three basic psychological needs are satisfied, both in intrinsic motivation and identified regulation. Intrinsic motivation is supported in the classroom setting because Teacher 3 can carry out teaching tasks autonomously, which implies the satisfaction of needs for autonomy and competence. Likewise, the school community supports intrinsic motivation, as Teacher 3 feels loved by peers, in such a way that the need for relatedness is also satisfied. Regarding identified regulation, it is supported because Teacher 3 promotes social constructivism in teaching tasks, thus encouraging the holistic development of students. In this regard, the needs for autonomy and competence are satisfied as the collaborative learning environment is the foundation of classroom settings. Lastly, the satisfaction of the need for relatedness also supports identified regulation because Teacher 3 values endeavours by the school community to enhance the conditions of music education.

These findings suggest that the autonomous motivation of music teachers may be inhibited by at least 10 factors in classroom situations. More precisely, there are five internal factors:

- Classroom disturbances as work stressor.

- The impact of teaching on students' minds.

- Teacher responsibility.

- Teaching style.

- The controlled motivation for teaching.

Likewise, there are five external factors:

- Official curriculum for music education.

- School educational project.

- School community.

- Spanish education policy.

- Music teachers' isolation.

The interrelation between factors is illustrated in Figure 1. Specifically, the official curriculum grants teacher autonomy, but according to participants, such autonomy is fairly impractical in conditions where the time for music education is scarce. Thus, music teachers possess curricular autonomy, but it does not mean that they have time for acting 
autonomously in the classroom. In this context, the given autonomy is impeded by the Spanish education policy. Such interrelation is vital for understanding the inhibition of autonomous motivation in classroom settings because the Spanish education policy and official curriculum have an impact on the school educational project. Firstly, the lack of autonomy for acting affects the teaching style because teachers, focusing on contents for teaching rather than learning, are controlling the time. In this context, the controlled motivation for teaching makes sense because school activities would mainly involve interactions between a student and a repertoire. Such activities would rarely aim at musical socialisation. Therefore, music teachers do not often realise that teaching actions have an impact on students' minds.

In addition, controlled motivation for teaching does not encourage educators to assume responsibilities for classroom disturbances because they deal with disruptions by using authoritarian methods. Music teachers make an effort to conduct teaching tasks in a limited time frame, such that all disruptions are understood as wasted time. In this scenario, music teachers get stressed because the limited time causes symbolic pressure in their minds due to the possibilities of noncompliance with the official curriculum. Finally, the autonomous motivation of music teachers is inhibited by school communities through the nondelivery of educational resources and the lack of curricular respect to music education. 


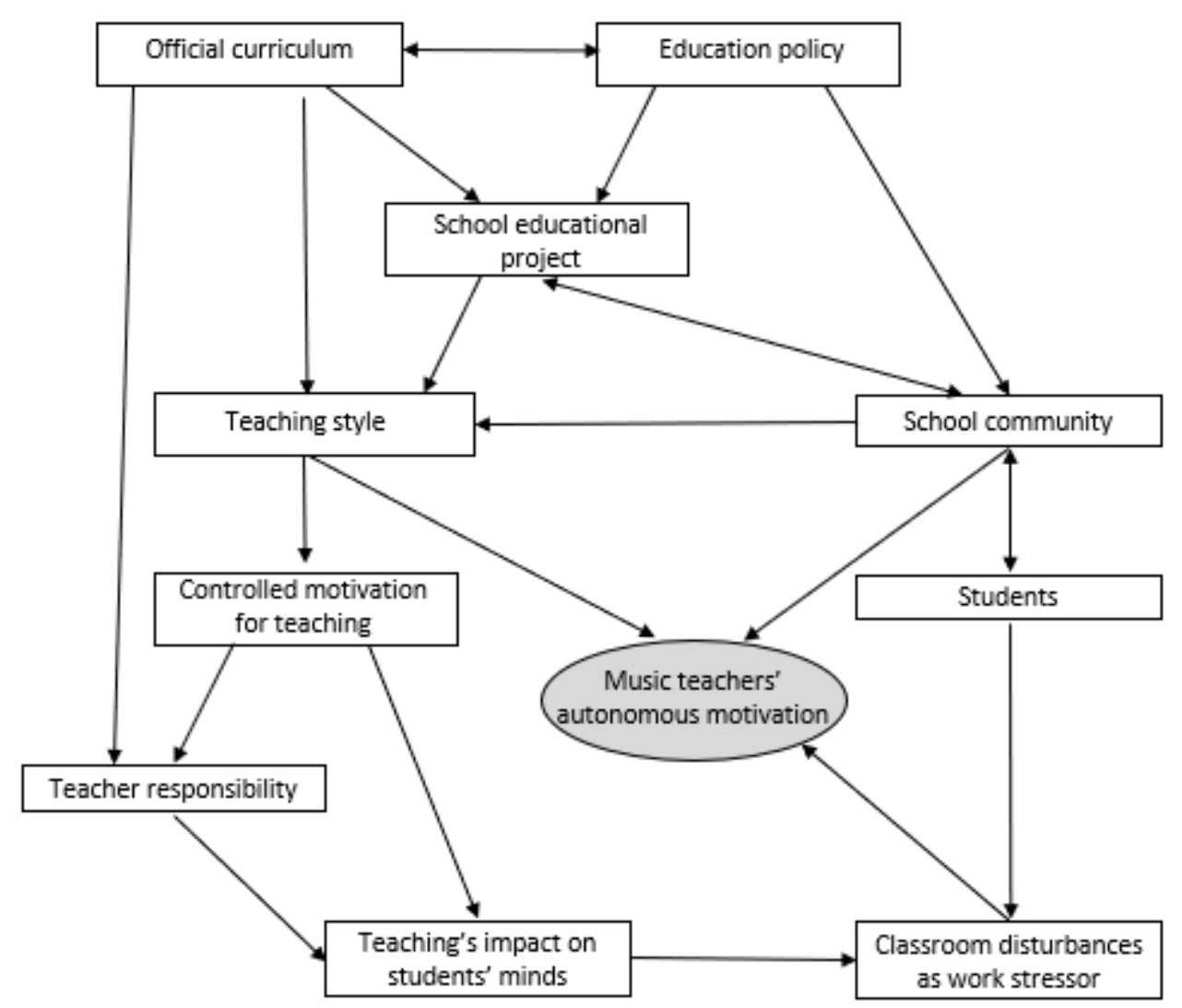

Figure 1. Objective portrait of the inhibition of music teachers' autonomous motivation. Source: Own elaboration.

It is important to consider that music teachers spend less time in schools than educators who teach subjects assessed through standardised tests because the curricular time for music education is shorter. In this context, music teachers have difficulties interacting with colleagues in pedagogical terms, at least in supportive matters for enhancing instruction and assessment in music education. The music teachers' isolation is then encouraged by the Spanish education policy and official curriculum (Figure 2), given that assessment tools for music education are different from strategies used by standardised tests. 


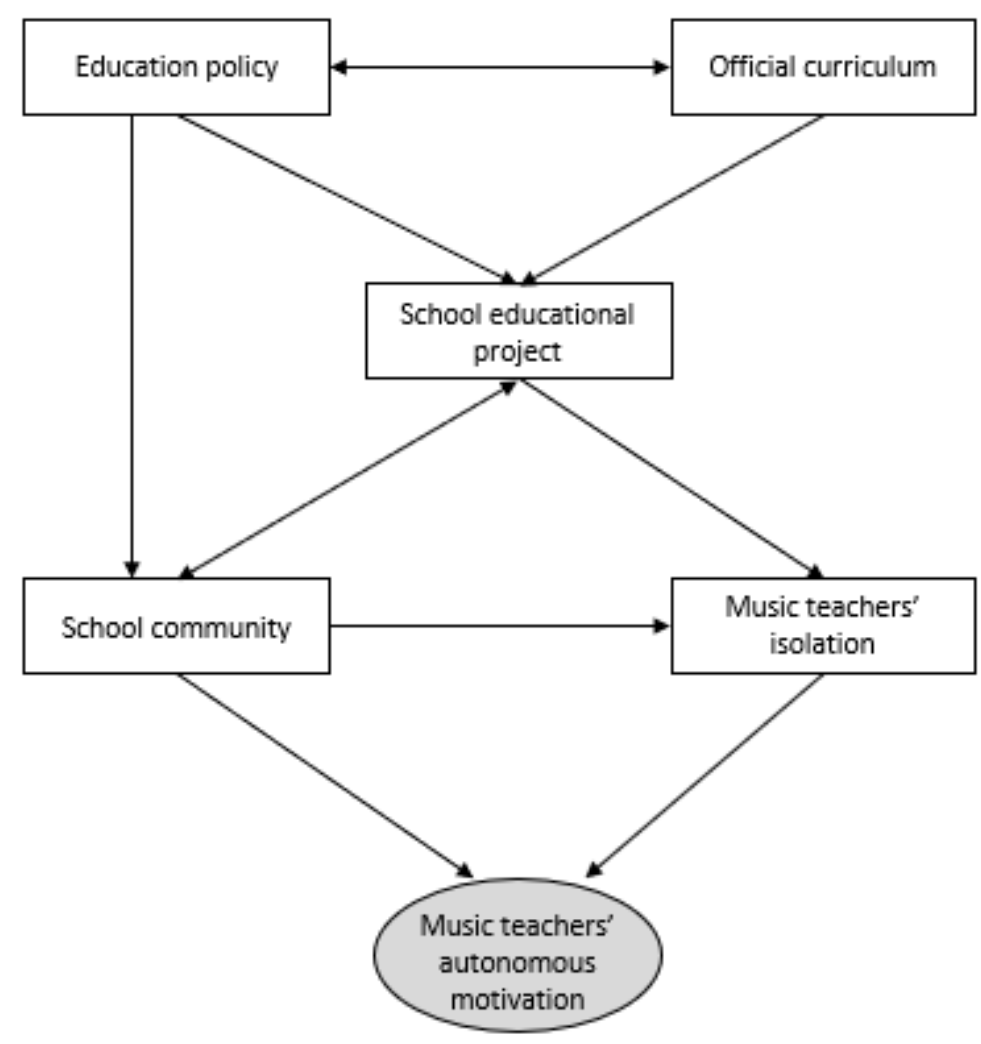

Figure 2. Inhibition of music teachers' autonomous motivation through external factors. Source: Own elaboration.

\section{Conclusions}

Based on the objective portrait, we can conclude that the autonomous motivation of music teachers in classroom settings is satisfied or thwarted by ideas that the members of the school community have about music education. In other words, contextual factors have an impact on teachers' minds. The concept of the school community is wide, as it includes principals, teachers, and parents or guardians. In this regard, it is imperative to delve into the school community in order to establish a more defined picture of the relationship between teachers and the members of the school community. Another determinant factor are the teachers' beliefs, as they are related to the school community and the society. In this study, personal beliefs were detected in the situations of classroom disruptions, but it is conceivable that they also affect other areas of music teaching. Future studies linked to occupational psychology should take personal beliefs into account. 
All these findings are useful for establishing some practical implications. Firstly, it is important to strengthen relationships between teachers and students because some teaching styles could serve as an emotional barrier during interactions. Secondly, it is also essential that members of the school community demonstrate respect for music education. That way, learners would assign more importance to musical activities in their daily routines and music teachers would feel more respected in their workplaces. Lastly, it is imperative that students play an active role in learning activities, by giving their opinions, undertaking school projects, or proposing learning units.

\section{References}

ANGEL-ALVARADO, R., \& ÁLAMOS, J. E. (2018). Musical Conducting in the Guitárregas Guitar Ensemble: A Leadership Based on the Self-determination of Music Teachers. Revista Internacional de Educación Musical, 6, 1, 53-61. doi:10.1177/230748411800600105

ANGEL-ALVARADO, R., WILHELMI, M. R., \& BELLETICH, O. (2018). Holistic Architecture for Music Education: A proposal for empirical research in educational 
situations. In J. Domenech, P. Merello, E. de la Poza, \& D. Blazquez (Eds.) 4th International Conference on Higher Education Advances (pp. 751-757). Valencia: Editorial Universitat Politècnica de València. doi:10.4995/HEAd18.2018.8079

ANGEL-ALVARADO, R., WILHELMI, M. R., \& BELLETICH, O. (2019). Holistic Architecture for Music Education: A research design for carrying out empiric and interdisciplinary studies in didactics of music. Itamar, 5, 335-357.

ANGEL-ALVARADO, R., WILHELMI, M. R., \& BELLETICH, O. (2020). Teaching autonomy: Does Spanish education system achieve the desired effect?. Psychology, Society, \& Education, 12, 1, 85-96. doi:10.25115/psye.v0i0.2585

CARRERO, V., SORIANO, R. \& TRINIDAD, A. (2012). Teoría fundamentada Grounded theory: El desarrollo de la teoría desde la generalización conceptual. Madrid: Centro de Investigaciones Sociológicas.

DAVENPORT, E. C., DAVISON, M., LIOU, P., \& LOVE, Q. (2015). Reliability, dimensionality, and internal consistency as defined by Cronbach: Distinct albeit related concepts. Educational Measurement: Issues and practice, 34, 4, 4-9. doi:10.1111/emip.12095

DECI, E. L., \& RYAN, R. M. (2016). Optimizing students' motivation in the Era of testing and pressure: A self-determination theory perspective. In W. Liu, J. Wang, \& R. M. Ryan (Eds), Building Autonomous Learners (pp. 9-29). Singapore: Springer.

ELLIOTT, D. J., \& SILVERMAN, M. (2015). Music matters: A philosophy of music education. New York: Oxford University Press.

EVANS, P. (2015). Self-determination theory: An approach to motivation in music education. Musicae Scientiae, 19, 1, 65-83. doi:10.1177/1029864914568044

FAUTLEY, M. (2010). Assessment in music education. Oxford: Oxford University Press.

FERNET, C., SENÉCAL, C., GUAY, F., MARSH, F. Y DOWSON, M. (2008). The work tasks motivation scale for teachers (WTMST). Journal of career assessment, 16, 2, 256-279. doi:10.1177/1069072707305764 
GABNYTÉ, G., \& STRAKŠIENÉ, D. (2014). Occupational motivation of music teachers as significant factor of social wellbeing. Social Welfare: Interdisciplinary Approach, 4, 1, 64-70.

GAGNÉ, M., \& DECI, E. L. (2005). Self-determination theory and work motivation. Journal of Organizational Behavior, 26, 4, 331-362.

JUNTUNEN, M-L. (2017). National assessment meets teacher autonomy, national assessment of learning outcomes in music in Finnish basic education. Music Education Research, 19, 1, 1-16. doi:10.1080/14613808.2015.1077799

KLINE, T. J. B. (2005). Psychological testing: A practical approach to design and evaluation. Thousand Oaks: SAGE.

MELLINGER, C. D., \& HANSON, T. A. (2017). Quantitative research methods in translation and interpreting studies. Abingdon: Routledge.

RUÍZ, M. (2015). Soporte de autonomía y motivación en educación: Consecuencias a nivel global y contextual (Doctoral thesis), Universitas Miguel Hernández, Elche, Spain.

RYAN, R. M., \& DECI, E. L. (2017). Self-Determination Theory: Basic psychological needs in motivation, development, and wellness. New York: The Guilford Press.

SAN MARTÍN, D. (2014). Teoría fundamentada y Atlas.ti: Recursos metodológicos para la investigación educativa. Revista electrónica de investigación educativa, 16, 1, 104122.

UNESCO. (2012). International Standard Classification of Education: ISCED 2011. Montreal: UNESCO Institute for Statistics.

WEST, C. (2013). Motivating music students: A review of the literature. National Association for Music Education, 31, 2, 11-19. doi:10.1177/8755123312473611

Word account in the manuscript: $\mathbf{5 1 1 8}$ words. 